\title{
ANALISIS KOREKSI FISKAL DALAM RANGKA PERHITUNGAN PPH BADAN PT. KAWANUA DASA PRATAMA
}

\author{
Felix Daniel Wongso \\ Jantje Tinangon \\ Stanley Walandouw \\ Fakultas Ekonomi dan Bisnis Jurusan Akuntansi \\ Universitas Sam Ratulangi Manado \\ email: lize_la_twice@yahoo.com
}

\begin{abstract}
ABSTRAK
PT. Kawanua Dasa Pratama adalah sebuah perusahaan yang merupakan Wajib Pajak berbentuk badan yang memiliki tanggung jawab untuk menghitung, menyetorkan dan melaporkan pajak terutang yang harus dibayarkan kepada Negara. Tetapi, terdapat suatu masalah yang akan dihadapi dalam pembayaran pajak. Hal ini disebabkan pada laporan keuangan khususnya laporan rugi - laba yang mempunyai laporan Laba Rugi Komersial dan Laporan Laba Rugi Fiskal.Keduanya jelas berbeda dilihat dari Laba Komersial yang mengacu pada Standar Akuntansi Keuangan yang berlaku, sedangkan Laba Fiskal mengacu pada Undang - Undang Perpajakan yang berlaku.Perbedaan ini sederhananya terdapat pada adanya pendapatan maupun biaya yang diakui sebagai pendapatan maupun biaya oleh perusahaan tetapi tidak diakui oleh Pajak. Perbedaan tersebut memerlukan suatu penyesuian atau rekonsiliasi agar jumlah PPh Badan Terutang yang dihitung oleh perusahaan dan pajak bisa sama. Untuk itu tujuan dari penelitian ini adalah untuk mengetahui laba rugi fiskal yang didapat dari hasil koreksi fiskal pada laporan keuangan komersial. Dalam penelitian ini, didapat laba setelah koreksi fiskal sebesar Rp 2.241.020.568 dan harus membayar pajak sebesar Rp 560.255.142.
\end{abstract}

Kata Kunci : Pajak Terutang, Laba Rugi, Koreksi Fiskal

\begin{abstract}
PT.Kawanua Dasa Pratama is a company which is a resident and as an entity that has the responsibility to calculate, report, and deposit the tax payable to be paid to the State. However, there are problems that will occurred in the payment of taxes. This is due to the particular financial reports, especially income statement have commercial income statement and fiscal income statement. Both of them are distinctly different, from some point of views about Profit Commercial that refers to the Financial Accounting Standards, while referring to the Act Taxable Income - Tax Act applicable. These differences are simply found in the presence of income and expenses are recognized as income or expense by the company but are not recognized by the Tax. These differences require an adjustment or reconciliation so that the amount of corporate income tax payable are calculated by the company and the tax could be alike. The purpose of this study is to determine the fiscal income statement derived from the financial statements of fiscal correction in the commercial. In this study, obtained after correction of the fiscal profit of $\operatorname{Rp} 2.241 .020 .568$ and had to pay tax of Rp 560.255.142.
\end{abstract}

Key Words : Tax due, Income Statement, Fiscal Correction 


\section{PENDAHULUAN}

\section{Latar Belakang}

Laporan laba rugi merupakan sesuatu hal yang amat penting dalam laporan keuangan. Di dalam laporan laba rugi ini menyajikan pendapatan (revenue), biaya (expenses) serta laba atau rugi (profit / losses) suatu perusahaan dalam periode atau masa waktu tertentu. Laporan ini sangat berguna untuk mengukur seberapa baik atau buruknya kinerja dari suatu perusahaan yang ada. Laporan ini biasanya disajikan pada masanya yaitu perbulan atau pun pertahun.

Laporan laba rugi ini sendiri juga merupakan suatu laporan keuangan yang harus dihasilkan dari sistem akuntansi, baik yang dibuat berdasarkan dengan ketentuan yang dalam Undang - Undang Perpajakan maupun yang ditetapkan berdasarkan Standar Akuntansi Keuangan (SAK). Secara mendasar, kedua hal ini ( Undang - Undang Perpajakan dan Standar Akuntansi Keuangan) mengatur suatu hal yang sama yakni tentang seberapa besar jumlah yang dibebankan kepada konsumen. Namun dalam koreksi fiskal, kita dapat menemukan suatu hal yang berbeda. Perbedaan ini terjadi apabila dari sisi Akuntansi penghasilan diukur terlalu rendah dan tidak wajar dikarenakan adanya perlakuan khusus yang mendukung terjadinya hal ini. Koreksi fiskal itu sendiri merupakan suatu koreksi atau penyesuaian yang harus dilakukan wajib pajak sebelum menghitung Pajak Penghasilan bagi wajib pajak badan dan wajib pajak pribadi yang menggunakan pembukuan dalam penghitungan penghasilan kena pajak. Walaupun prinsip perbedaan ini tidak bertentangan berdasarkan konsep dasar, prinsip, metode atau ketentuan yang berlaku dalam prinsip akuntansi keuangan dan akuntansi perpajakan. Namun, dalam beberapa hal harus diakui memang terdapat perbedaan, sehingga sepantasnya apabila laporan laba rugi yang dihasilkan oleh kedua disiplin akuntansi ini juga berbeda.

Perbedaan yang nyatanya adalah bagi perusahaan yang menganut prinsip dasar keuangan (SAK) berpendapat bahwa pendapatan yang akan menambah laba kena pajak dan semua pengeluaran adalah beban yang akan mengurangi laba kena pajak. Hal ini berbeda dengan undang - undang perpajakan yang tidak mengakui semua pemasukan sebagai faktor penambahan laba kena pajak, serta ada beberapa jenis pendapatan yang bukan merupakan faktor penambah laba kena pajak karena pendapatan tersebut sudah dikenakan pajak bersifat final (tidak dapat dipungut lagi) dan tidak semua pengeluran adalah faktor pengurang laba kena pajak karena ada beberapa jenis pengeluran yang sesungguhnya bukan merupakan bagian dari kegiatan perusahaan.

Dalam periode yang berjalan sebuah badan pasti telah membuat suatu laporan keuangan yang termasuk di dalamnya laporan laba rugi yang memuat penghasilan, biaya dan laba rugi. Seluruh penghasilan dan biaya yang terjadi dalam perusahaan perlu dilaporkan semua sehingga dalam menghitung pajak penghasilannya perlu dilakukan sebuah koreksi atau pos pos yang tidak dapat dimasukan dalam perhitungan PPh Badan. Koreksi inilah yang biasanya disebut koreksi fiskal. PT. Kawanua Dasa Pratama adalah salah satu perusahaan yang cukup berkembang di Manado di bidang super market. Hal ini terbukti dengan masih eksisnya perusahaan ini selama lebih dari 10 tahun beroperasi di kota Manado. Atas dasar inilah penulis ingin mengamati bagaimana perusahaan ini menyikapi perbedaan - perbedaan yang terjadi di antara laba rugi komersial dan laba rugi fiskal berdasarkan Standar Akuntansi Keuangan dan serta Undang - Undang Perpajakan yang berlaku dengan mengangkat topik "Analisis Koreksi Fiskal dalam rangka perhitungan PPh Badan pada PT Kawanua Dasa Pratama" 


\section{Tujuan Penelitian}

Tujuan penelitian ini untuk mengetahui koreksi fiskal yang dilakukan PT. Kawanua Dasa Pratama dalam rangka perhitungan PPh Badan.

\section{TINJAUAN PUSTAKA}

\section{Pengertian Akuntansi}

Warren dkk (2005 : 10) akuntansi dapat didefinisikan sebagai sistem informasi yang menghasilkan laporan kepada pihak - pihak yang berkepentingan mengenai aktivitas ekonomi dan kondisi perusahaan.

Horngren \& Harrison (2007 : 54) menyatakan bahwa Akuntansi adalah sistem informasi yang mengukur aktivitas bisnis, memproses data menjadi laporan, dan mengkomunikasikan hasilnya kepada para pengambil keputusan.

\section{Laporan Keuangan}

Laporan keuangan adalah catatan informasi keuangan suatu perusahaan pada suatu periode akuntansi yang dapat digunakan untuk menggambarkan kinerja perusahaan tersebut. Laporan keuangan adalah bagian dari proses pelaporan keuangan. Laporan keuangan juga berguna untuk menyampaikan informasi keuangan yang dipercaya kepada pihak yang berkepentingan.

Soemarso (2006 : 430) laporan keuangan adalah hubungan antara suatu angka dalam laporan keuangan dengan angka lain yang mempunyai makna atau dapat menjelaskan arah perubahan (trend) suatu fenomena.

\section{Pengertian Akuntansi Pajak}

Akuntansi pajak adalah akuntansi yang diterapkan dengan tujuan untuk menetapkan besarnya pajak terhutang. Fungsi akuntansi pajak ini adalah untuk mengolah data kuantitatif yang akan digunakan untuk menyajikan laporan keuangan yang memuat perhitungan perpajakan.

\section{Pengertian Pajak}

Mardiasmo (2011:1) Pajak adalah iuran rakyat pada kas negara berdasarkan Undang-Undang (yang dapat di paksakan) dengan tidak mendapat jasa timbal (kontra prestasi) yang langsung dapat di tunjukkan dan yang di gunakan untuk membayar pengeluaran umum.

\section{Fungsi Pajak}

(Mardiasmo 2011:1) Pajak merupakan sumber penerimaan Negara yang mempunyai dua fungsi yaitu :

1. Fungsi Anggaran (budgetair) sebagai sumber dana bagi pemerintah, untuk membiayai pengeluaran - pengeluarannya.

2. Fungsi mengatur (regulerend) sebagai alat pengatur atau melaksanakan pemerintah dalam bidang social ekonomi.

\section{Konsep Koreksi Fiskal}

Koreksi fiskal merupakan suatu penyesuaian yang dilakukan sebelum menghitung Pajak Penghasilan bagi wajib pajak badan dan wajib pajak pribadi. Penyesuaian ini biasanya 
dilakukan karena adanya perbedaan pengakuan penghasilan antara akuntansi fiskal dengan akuntansi komersial.

\section{Jenis Koreksi Fiskal}

Terdapat dua jenis koreksi fiskal yaitu koreksi fiskal positif dan koreksi fiskal negatif. Koreksi fiskal positif adalah koreksi / penyesuaian yang akan mengakibatkan meningkatnya laba kena pajak yang pada akhirnya akan membuat PPh Badan Terhutangnya juga akan meningkat.Sedangkan koreksi fiskal negatif adalah koreksi atau penyesuaian yang akan mengakibatkan menurunnya laba kena pajak yang akan membuat PPh badan terhutangnya juga akan menurun.

\section{Definisi Pajak Penghasilan}

Menurut Prabowo (2008:34) pajak penghasilan adalah suatu pengutan resmi yang ditujukan kepada masyarakat yang berpenghasilan yang diterima dan diperoleh dalam tahun pajak, untuk kepentingan Negara dan masyarakat dalam hidup berbangsa dan bernegara sebagai suatu kewajiban yang harus dilaksanakan.

Resmi (2009:41) mengemukakan definisi pajak penghasilan adalah pajak yang dikenakan terhadap subjek pajak atas penghasilan yang diterima atau diperoleh dalam suatu tahun pajak.

\section{Penelitian Terdahulu (Kajian Empiris)}

\begin{tabular}{|c|c|c|c|c|c|c|}
\hline $\begin{array}{l}\text { Nama } \\
\text { Peneliti/tahu } \\
\text { n }\end{array}$ & Judul & Tujuan & $\begin{array}{l}\text { Metode } \\
\text { Penelitian }\end{array}$ & $\begin{array}{l}\text { Hasil } \\
\text { Penelitian }\end{array}$ & Persamaan & Perbedaan \\
\hline $\begin{array}{l}\text { Prang } \\
\text { Buwono } \\
(2012)\end{array}$ & $\begin{array}{l}\text { Analisis } \\
\text { Koreksi Fiskal } \\
\text { atas Laporan } \\
\text { Keuangan } \\
\text { pada } \\
\text { CV.Reviana }\end{array}$ & $\begin{array}{l}\text { Untuk } \\
\text { menghitung } \\
\text { penghasilan } \\
\text { yang dapat } \\
\text { agar } \\
\text { mengetahui } \\
\text { Penghasilan } \\
\text { Kena Pajak } \\
\text { menurut } \\
\text { laporan } \\
\text { keuangan } \\
\text { fiskal yang } \\
\text { menjadi dasar } \\
\text { perhitungan } \\
\text { PPh badan } \\
\text { Terhutang. }\end{array}$ & $\begin{array}{l}\text { analisis } \\
\text { kualitatif }\end{array}$ & $\begin{array}{l}\text { Terdapat } \\
\text { beberapa akun } \\
\text { perbedaan } \\
\text { pengakuan } \\
\text { penghasilan dan } \\
\text { biaya setelah } \\
\text { direkonsiliasi. }\end{array}$ & $\begin{array}{l}\text { Meneliti } \\
\text { dampak } \\
\text { laporan } \\
\text { keuangan } \\
\text { yang telah } \\
\text { direkonsiliasi } \\
\text { terhadap } \\
\text { pemungutan } \\
\text { pajak }\end{array}$ & 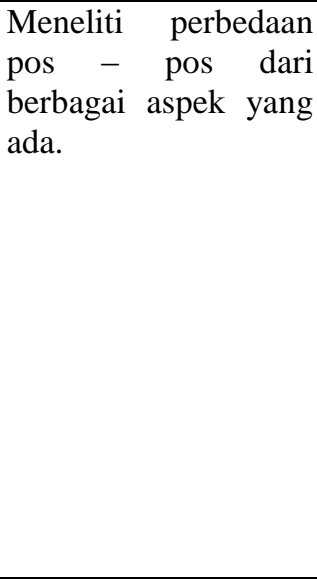 \\
\hline $\begin{array}{l}\text { Dewi Yuniarti } \\
(2008)\end{array}$ & $\begin{array}{l}\text { Rekonsiliasi } \\
\text { Fiskal } \\
\text { Atas Laporan } \\
\text { Keuangan } \\
\text { Komersial } \\
\text { Untuk } \\
\text { Menentukan } \\
\text { Pajak } \\
\text { penghasilan } \\
\text { (Studi pada } \\
\text { Laporan } \\
\text { Keuangan } \\
\text { Tahun 2007 } \\
\text { PT. BPR } \\
\text { Nusamba } \\
\text { Ngunut } \\
\text { Tulungagung) }\end{array}$ & $\begin{array}{l}\text { Untuk } \\
\text { menentukan } \\
\text { nilai pajak } \\
\text { penghasilan } \\
\text { terutang } \\
\text { perusahaan } \\
\text { dengan } \\
\text { melakukan } \\
\text { rekonsilias } \\
\text { i laporan } \\
\text { keuangan } \\
\text { komersial } \\
\text { menjadi } \\
\text { laporan } \\
\text { keuangan } \\
\text { fiskal. }\end{array}$ & $\begin{array}{l}\text { analisis } \\
\text { kualitatif }\end{array}$ & $\begin{array}{l}\text { Menunjukkan } \\
\text { adanya } \\
\text { beda antara laba } \\
\text { akuntansi } \\
\text { dengan } \\
\text { laba untuk } \\
\text { tujuan pajak } \\
\text { yang dialami } \\
\text { PT. } \\
\text { Nusamba } \\
\text { Ngunut } \\
\text { Tulungangagun } \\
\text { g }\end{array}$ & $\begin{array}{l}\text { Merekonsilias } \\
\text { i antara laba } \\
\text { komersial } \\
\text { dengan laba } \\
\text { fiskal. }\end{array}$ & $\begin{array}{l}\text { Objek dan waktu } \\
\text { Penelitian sehingga } \\
\text { hasil penelitiannya } \\
\text { pun berbeda. }\end{array}$ \\
\hline
\end{tabular}




\section{METODE PENELITIAN}

\section{Jenis Penelitian}

Penelitian ini menggunakan metode penelitian deskriptif kualitatif karena dalam pelaksanaannya meliputi data, analisis dan interpretasi tentang arti dan data yang diperoleh.Metode Deskriptif adalah suatu metode dalam meneliti status kelompok manusia, suatu objek, suatu set kondisi, suatu sistem pemikiran, ataupun suatu kelas peristiwa pada masa sekarang (Nazir, 2005 : 54). Sedangkan metode penelitian kualitatif adalah penelitian yang berlandaskan pada filsafat postpositifme, digunakan untuk meneliti pada kondisi objek yang alamiah dimana peneliti adalah sebagai instrument kunci, pengambilan sample sumber dan data dilakukan secara purposive, teknik pengumpulan data dilakukan dengan triangulasi (gabungan) analisis data bersifat induktif/kualitatif, dan hasil penelitian kualitatif lebih menekankan pada makna daripada generalisasi (Sugiono, 2009 $: 15)$.

\section{Tempat dan Waktu Penelitian}

Tempat penelitian adalah pada kantor PT Kawanua Dasa Pratama yang terletak di Jl. Wolter Monginsidi 1 Kompleks perumahan Bahu Mall. Waktu penelitian dilakukan pada 23 Agustus 2013 sampai dengan 3 Desember 2013.

\section{Metode Pengumpulan Data}

Pengumpulan data dilakukan untuk memperoleh informasi yang dibutuhkan dalam rangka mencapai tujuan penelitian (Gulo, 2012 : 110). Dalam proses mengumpulan data yang diperlukan untuk perusahaan, penulis menggunakan 2 teknik pengumpulan data yaitu :

A. Wawancara : Penulis berusaha memewancarai dan bertanya kepada sumber terpercaya perusahaan terutama di bidang pajak agar dapat mendapatkan informasi yang baik dan relevan.

B. Dokumentasi : Penulis mendapatkan informasi - informasi yang dibutuhkan dari dokumen dokumen perusahaan tentang pajak serta laporan keuangan yang telah dibuat.

\section{Metode Analisis}

Analisis yang digunakan penulis untuk menyelesaikan permasalahan dalam penulisan ini adalah dengan menggunakan analisis deksripftif kualitatif. Kirk dan Miller (2010: 4) mendefinisikan metode kualitatif sebagai suatu tradisi dalam ilmu pengetahuan yang bergantung pada pengamatan seseorang.

\section{HASIL PENELITIAN DAN PEMBAHASAN}

\section{Gambaran Umum dan Sejarah PT. Kawanua Dasa Pratama}

PT. Kawanua Dasa Pratama adalah perusahaan yang bergerak dibidang supermarket. Perusahaan yang terbentuk pada 19 Maret 2002 atau dengan kata lain telah eksis selama lebih dari 11 tahun ini juga menggambarkan bagaimana Fresh Mart Supermarket telah mendapatkan tempat yang lebih di hati masyarakat kota Manado dalam hal perbelanjaan.

Fresh Mart sendiri telah membuka beberapa cabang yang telah tersebar di kota Manado. Cabang Fresh Mart yang pertama yaitu "Fresh Mart Kembang" yang dibuka pada 8 Desember 2008.

Melihat antusiasme masyarakat yang cukup positif menyambut cabang pertama dari Fresh Mart maka Fresh Mart juga berusaha untuk membuka cabang - cabangnya yang lain hal ini dapat dilihat dengan dibukanya Fresh Mart Teling pada 23 Agustus 2009, Fresh Mart Winangun pada tanggal 13 November 2010 dan cabang terakhir yaitu Fresh Mart Wonasa pada tanggal 4 Agustus 2011.

Sampai saat ini, Fresh Mart telah mempekerjakan 281 orang karyawan per 31 Oktober 2013. Para karyawan ini tersebar dari Fresh Mart pusat (Fresh Mart Bahu) serta ke cabang - cabang ( Fresh Mart 
Kembang, Teling, Winangun, dan Wonasa). Setiap karyawan memiliki peran dan tugas masingmasing. Setiap elemen dari pekerja, dari atasan sampai bawahan memiliki peran dan tugas masing masing yang saling berhubungan dan sangat mempengaruhi kinerja dari Fresh Mart itu sendiri. Terganggunya suatu elemen pekerjaan dapat mengganggu elemen - elemen lainnya dalam struktur Fresh Mart. Karena itu Fresh Mart sangat menekankan kepada kemajuan setiap karyawan yang bekerja.

\section{Hasil Penelitian}

Berikut ini adalah laporan rugi - laba PT. Kawanua Dasa Pratama per 31 Desember 2012

\section{Pendapatan}

Penjualan BKP

Penjualan non BKP

Pendapatan Sewa

Pendapatan Sewa (Final)

Total Pendapatan

\section{Harga Pokok Penjualan}

Persediaan Awal

Pembelian BKP

Pembelian NON BKP

RET/POL.PBL BKP

RET/POT.BPL NON BKP

Persediaan Akhir

Total HPP

Laba Bruto

\section{Biaya Operasi}

Biaya Gaji Karyawan

Biaya Promosi

Biaya Pemeliharaan \& Keamanan

Biaya PAM

Biaya Listrik

Biaya Pajak Daerah

Biaya Telpon

Biaya Keperluan Super Market

Biaya Alat Tulis Menulis

Biaya Percetakan/Fotocopy

Biaya Kendaraan/Suku cadang

Biaya Pemeliharaan Kendaraan

Biaya BBM/Transport/Parkir

Biaya Peralatan \& Perlengkapan

Biaya Administrasi Bank / Provinsi

Biaya Bunga Bank

Biaya Asuransi

Biaya Sewa

Biaya Penyusutan

PPH Pasal 21

\section{PT KAWANUA DASA PRATAMA \\ RUGI-LABA \\ PER 31 DESEMBER 2012}

\begin{tabular}{lr} 
Rp. & $90.496 .531 .623,00$ \\
Rp & $26.644 .805 .844,00$ \\
$R p$ & $529.116 .352,00$ \\
$R p$ & $274.227 .273,00$ \\
\hline
\end{tabular}

Rp 117.944.681.092

Rp 12.803.487.475,00

Rp 83.622.211.917,00

Rp 20.199.429.907,00

Rp $\quad(712.947 .103,00)$

Rp $\quad(8.563 .963,00)$

$\underline{\operatorname{Rp}(10.173 .907 .608,00)}$

$\underline{\operatorname{Rp} 105.729 .710 .625}$

Rp 12.214.970.467
$\mathrm{Rp} \quad 4.481 .740 .000,00$

Rp $\quad 69.863 .636,00$

Rp $\quad 241.831 .567,00$

Rp $\quad 31.228 .001,00$

Rp $\quad 3.159 .228 .444,00$

$\mathrm{Rp} \quad 108.043 .327,00$

Rp $\quad 99.665 .083,00$

Rp $\quad 283.486 .528,00$

$\mathrm{Rp} \quad 12.555 .232,00$

$\mathrm{Rp} \quad 1.023 .600,00$

Rp $\quad 16.077 .000,00$

Rp $\quad 7.438 .646,00$

Rp $\quad 50.696 .842,00$

$\mathrm{Rp} \quad 40.821 .184,00$

$\mathrm{Rp} \quad 11.766 .500,00$

Rp $\quad 513.804 .681,70$

Rp $\quad 74.788 .382,00$

Rp $\quad 55.000 .000,00$

Rp 421.164.052,59

Rp $\quad 47.315 .063,00$ 
PPH Pasal 23

PPH Pasal 4 ayat 2

PPH Pasal 25/29

PPH Jasa Giro

Biaya Jamsostek

SKPKB/STP

Biaya Lainnya

Total biaya Operasi

Laba bersih

\section{Non Operasi}

Jasa Giro

Total biaya non Operasi

Laba/Rugi

$\begin{array}{lr}\text { Rp } & 10.582 .738,00 \\ \text { Rp } & 27.422 .663,00 \\ \text { Rp } & 549.672 .262,00 \\ \text { Rp } & 2.567 .310,13 \\ \text { Rp } & 167.008 .750,00 \\ \text { Rp } & 204.817 .979,00 \\ \text { Rp } & 19.499 .919,30\end{array}$

$\underline{\operatorname{Rp} 10.709 .109 .390,72}$

$\mathrm{Rp} \quad 12.836 .527,66$

Dari data yang ada, dapat dilihat bahwa PT. Kawanua Dasa Pratama belum melakukan penyesuaian untuk pembayaran pajak. Dari data yang ada, terlihat bahwa PT. Kawanua Dasa Pratama mengalami keuntungan sebesar Rp 1.518.697.603,94 tetapi data itu hanya berdasarkan laporan keuangan yang ada tanpa dilakukan rekonsiliasi. Hal ini menunjukan bahwa PT. Kawanua Dasa Pratama mengikuti Laporan Keuangan berdasarkan Standar Akuntansi Keuangan bukan mengikuti Undang - Undang Perpajakan.

\section{Pembahasan}

Dalam hasil penelitian pada PT. Kawanua Dasa Pratama, dapat dilihat bahwa perusahaan telah mencoba mengeluarkan suatu laporan laba - rugi yang sesuai dengan Standar Akuntansi Keuangan tapi belum memegang prinsip Undang - Undang Perpajakan. Hal ini membuat sistem pembayaran pajak jadi terganggu, akan lebih baik jika dalam laporan laba - rugi juga di masukan data koreksi fiskal positif dan juga negatif seperti yang akan di paparkan berikut ini.

\section{PT KAWANUA DASA PRATAMA RUGI-LABA \\ PER 31 DESEMBER 2012}

\section{Pendapatan}

Penjualan BKP

Penjualan non BKP

Pendapatan Sewa

Pendapatan Sewa (Final)

Total Pendapatan

\section{Harga Pokok Penjualan \\ Persediaan Awal \\ Pembelian BKP \\ Pembelian NON BKP \\ RET/POL.PBL BKP \\ RET/POT.BPL NON BKP \\ Persediaan Akhir \\ Total HPP \\ Laba Bruto}

\section{Biaya Operasi}

Biaya Gaji Karyawan

Biaya Promosi
Rp. $90.496 .531 .623,00$

Rp 26.644.805.844,00

Rp $\quad 529.116 .352,00$

Rp 274.227.273,00

Rp 117.944.681.092

Rp 12.803.487.475,00

Rp 83.622.211.917,00

Rp 20.199.429.907,00

Rp $\quad(712.947 .103,00)$

Rp $\quad(8.563 .963,00)$

Rp $(10.173 .907 .608,00)$

$\underline{\mathrm{Rp} 105.729 .710 .625}$

Rp 12.214.970.467

Rp $\quad 4.481 .740 .000,00$

Rp $\quad 69.863 .636,00$ 


Biaya Pemeliharaan \& Keamanan
Biaya PAM
Biaya Listrik
Biaya Pajak Daerah
Biaya Telpon
Biaya Keperluan Super Market
Biaya Alat Tulis Menulis
Biaya Percetakan/Fotocopy
Biaya Kendaraan/Suku cadang
Biaya Pemeliharaan Kendaraan
Biaya BBM/Transport/Parkir
Biaya Peralatan \& Perlengkapan
Biaya Administrasi Bank / Provinsi
Biaya Bunga Bank
Biaya Asuransi
Biaya Sewa
Biaya Penyusutan
PPH Pasal 21
PPH Pasal 23
PPH Pasal 4 ayat 2
PPH Pasal 25/29
PPH Jasa Giro
Biaya Jamsostek
SKPKB/STP
Biaya Lainnya
Total biaya Operasi
Laba bersih
Non Operasi
Jasa Giro
Total biaya non Operasi
Laba/Rugi

$\begin{array}{lr}\text { Rp } & 241.831 .567,00 \\ \mathrm{Rp} & 31.228 .001,00 \\ \mathrm{Rp} & 3.159 .228 .444,00 \\ \mathrm{Rp} & 108.043 .327,00 \\ \mathrm{Rp} & 99.665 .083,00 \\ \mathrm{Rp} & 283.486 .528,00 \\ \mathrm{Rp} & 12.555 .232,00 \\ \mathrm{Rp} & 1.023 .600,00 \\ \mathrm{Rp} & 16.077 .000,00 \\ \mathrm{Rp} & 7.438 .646,00 \\ \mathrm{Rp} & 50.696 .842,00 \\ \mathrm{Rp} & 40.821 .184,00 \\ \mathrm{Rp} & 11.766 .500,00 \\ \mathrm{Rp} & 513.804 .681,70 \\ \mathrm{Rp} & 74.788 .382,00 \\ \mathrm{Rp} & 55.000 .000,00 \\ \mathrm{Rp} & 421.164 .052,59 \\ \mathrm{Rp} & 47.315 .063,00 \\ \mathrm{Rp} & 10.582 .738,00 \\ \mathrm{Rp} & 27.422 .663,00 \\ \mathrm{Rp} & 549.672 .262,00 \\ \mathrm{Rp} & 2.567 .310,13 \\ \mathrm{Rp} & 167.008 .750,00 \\ \mathrm{Rp} & 204.817 .979,00 \\ \mathrm{Rp} & 19.499 .919,30 \\ & \end{array}$

$\underline{\operatorname{Rp} 10.709 .109 .390,72}$

Rp 1.505.861.076,28

$\operatorname{Rp} \quad 12.836 .527,66$
$\begin{array}{lr}\mathrm{Rp} & 12.836 .527,66 \\ \mathrm{Rp} & 1.518 .697 .603,94\end{array}$

Yang harus dilakukan penyesuaian diantaranya PPh pasal 21 yang didapat dari gaji karyawan, $\mathrm{PPh}$ pasal 25 yang telah di bayarkan di tiap akhir bulan yang merupakan angsuran untuk pajak yang akan dibayar di akhir tahun pada PPh pasal 29, PPh pasal 23 yang telah dibayarkan ini didapatkan dari potongan atas penghasilan yang diterima atau diperoleh Wajib Pajak dalam negeri yang diperoleh dari penggunaan harta atau modal, PPh pasal 4 ayat 2 merupakan pajak penghasilan yang didapatkan dari pendapatan sewa (final) sebesar 10\%, PPh Jasa Giro didapatkan dari Jasa Giro yang dipotong sebesar $20 \%$, biaya Jamsostek didapatkan dari seberapa besar kontribusi seseorang terhadap perusahaan yang merupakan bentuk perlindungan bagi tenaga kerja untuk mengatasi resiko sosial ekonomi setiap orang, biaya SKPKB/STP yang dihitung dari kantor pajak yang menilai kewajaran suatu perusahaan tentang seberapa besar pajak yang kurang dibayar berdasarkan laporan yang telah dibuat.

\section{Penyesuaian Fiskal Positif}

PPh Pasal 21

PPh Pasal 23

PPh Pasal 4 ayat 2

$\mathrm{PPh}$ Pasal 25/29

PPh Jasa Giro

Biaya Jamsostek

$\begin{array}{lr}\text { Rp } & 47.315 .063,00 \\ R p & 10.582 .738,00 \\ R p & 27.422 .738,00 \\ R p & 549.672 .262,00 \\ \text { Rp } & 2.567 .310,13 \\ R p & 167.008 .750,00\end{array}$


SKPKB/STP

Total penyesuaian fiskal positif

Total laba setelah koreksi fiskal positif

\section{Penyesuaian Fiskal Negatif}

Jasa Giro

Pendapatan Sewa (Final)

Total penyesuaian fiskal negative

Total laba setelah koreksi fiskal
$\underline{\operatorname{Rp} \quad 204.817 .979,00}$

Rp $\quad 1.009 .386 .765,13$

Rp $\quad 2.528 .084 .369,07$

$\mathrm{Rp} \quad 12.836 .527,66$

Rp 274.227.273,00

$\underline{\mathrm{Rp} \mathrm{287.063.800,66}}$

Rp 2.241.020.568,41

Dari data yang ada ini telah benar mengikuti Undang - Undang pajak yang berlaku. PPh Pasal 21 sebesar Rp 47.315.063,00 , PPh Pasal 23 sebesar Rp 10.582.738,00 , PPh pasal 4 ayat 2 sebesar 27.422.663,00 dan juga PPh pasal 25/29 sebesar 549.672.262,00 harus dilakukan koreksi fiskal positif dikarekan menurut peraturan perpajakan yang berlaku tentang pajak penghasilan menyatakan bahwa pajak penghasilan kecuali PPh pasal 26 (tidak termasuk dividen) sepanjang PPh dimaksud ditambah sebagai dasar perhitungan pajak untuk pemotongan $\mathrm{PPh}$ pasal 26 adalah merupakan beban yang tidak dapat dikurangi dari penghasilan bruto.

$\mathrm{PPh}$ Jasa Giro sebesar 2.567.310,13 harus dikoreksi ke rekonsiliasi positif karena merupakan suatu pajak penghasilan. Begitu juga dengan SKPKB/STP merupakan suatu sanksi administrasi pajak yang menurut Undang - Undang perpajakan harus dikoreksi secara positif.

Biaya Jamsostek harus dikoreksi secara positif dikarenakan bukan merupakan suatu biaya yang boleh dikurangkan dalam menentukan besarnya Penghasilan Kena Pajak.

Jasa giro sebesar Rp 12.836.517,66 serta Pendapatan Sewa (Final) sebesar Rp 274.227.273,00 harus dilakukan rekonsiliasi fiskal negatif karena beban merupakan objek pajak penghasilan. Hal ini disebabkan oleh pengenaan pajak yang bersifat final.

Peraturan perundangan pajak mengatakan bahwa untuk menghitung besaran pajak penghasilan badan yang harus dibayar adalah dengan cara mengalikan 25\% dari total laba kena pajak.

\section{PPh Badan $=25 \% \times$ Laba Kena Pajak}

Laba kena pajak PT. Kawanua Dasa Pratama sebelum dilakukan koreksi fiskal adalah sebesar Rp 1.518.697.603,94. Jadi jumlah pajak yang harus dibayar PT Kawanua Dasa Pratama sebelum dilakukan koreksi fiskal adalah sebagai berikut

$\mathrm{PPh}$ badan $=25 \% \mathrm{x}$ Laba Kena Pajak

$\mathrm{PPh}$ badan $=25 \%$ x 1.518.697.603,94 = Rp. 378.674.401

Sebelum dilakukan koreksi fiskal, PT. Kawanua Dasa Pratama harus membayar pajak sebesar Rp 378.674.401. Hal ini tentu akan berbeda setelah dilakukan koreksi fiskal. Laba kena pajak PT Kawanua Dasa Pratama yang sebelumnya Rp 1.518.697.603,94 berubah menjadi 2.241.020.568,41 setelah dilakukan koreksi fiskal.

$\mathrm{PPh}$ badan $=25 \% \times$ Laba Kena Pajak

$\mathrm{PPh}$ badan $=25 \%$ x 2.241.020.568,41 = Rp 560.255.142

Sesuai peraturan perpajakan, telah dilakukan beberapa koreksi fiskal yang meningkatkan laba kena pajak PT. Kawanua Dasa Pratama dan hal itu tentu saja mempengaruhi jumlah pajak yang harus dibayar. Sebelum dilakukan koreksi fiskal, PT Kawanua Dasa Pratama harus membayar pajak sebesar Rp 378.674.401. Setelah dilakukan koreksi fiskal, PT Kawanua Dasa Pratama harus membayar pajak sebesar Rp 560.255.142. Hal ini telah sesuai dengan Undang Undang Perpajakan yang berlaku. 


\section{PENUTUP}

\section{Kesimpulan}

Berdasarkan hasil penelitian yang telah dibuat, dapat ditarik kesimpulan yaitu :

PT Kawanua Dasa Pratama telah membuat laporan laba komersial dengan tepat dan telah membuat laporan laba fiskal sesuai dengan Undang - Undang perpajakan yang berlaku.

\section{Saran}

Berdasarkan pembahasan dan kesimpulan yang telah diuraikan, terdapat beberapa saran yang dapat diberikan untuk PT Kawanua Dasa Pratama, yaitu :

1. PT Kawanua Dasa Pratama sebaiknya menyertakan penyesuaian dalam membuat laporan rugi laba perusahaan.

2. Perusahaan harus lebih memperhatikan aspek - aspek yang harus dikoreksi fiskal agar supaya tidak terdapat kekeliruan dalam pembayaran pajak. 


\section{DAFTAR PUSTAKA}

Januarsi, Yeni. 2013. Laporan Keuangan Menurut PSAK http://newsakuntansi.blogspot.com/2013/05/pengertian-laporan-keuangan-menurut.html. Diakses Desember, 03 , 2013.

Mardiasmo, 2008. Perpajakan, Penerbit Andi. Yogyakarta.

Muljono, Djoko. 2007. Pengantar PPh dan PPh 21 lengkap dengan undang-undang. Penerbit Andi. Yogyakarta.

Muljono, Djoko. 2009. Akuntansi Pajak Edisi Revisi. Penerbit Andi. Yogyakarta.

Resmi, Siti. 2011. Perpajakan Teori dan Kasus. Penerbit Salemba Empat. Jakarta.

Setiawati, Lilis. 2009. Pedoman dan Cara pengisian SPT PPh pasal 21. Penerbit Andi. Yogyakarta.

Waluyo, 2011. Perpajakan Edisi 10- buku 1. Salemba Empat. Jakarta.

Waluyo, 2012. Perpajakan Indonesia 1. Salemba Empat. Jakarta.

Wicaksono, Baruni. 2009. Akuntansi Pajak Lanjutan. Penerbit Andi. Yogyakarta. 